\title{
Bibliometric analysis of organisational culture using CiteSpace
}

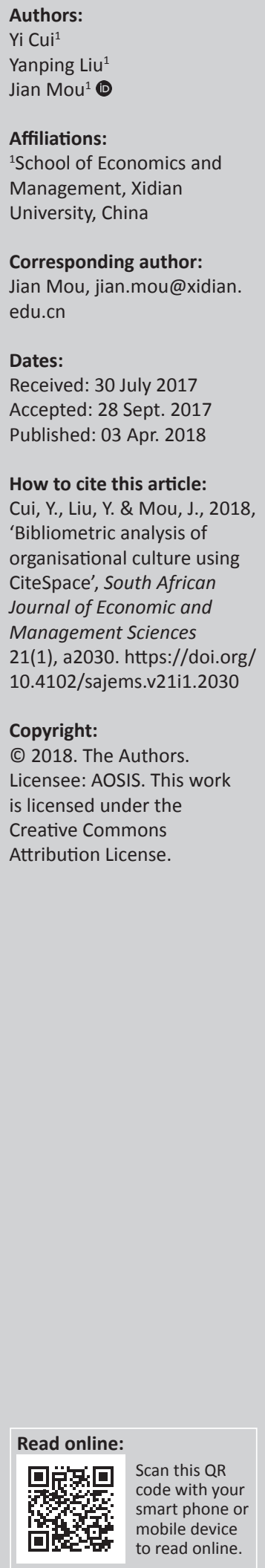

Background: As organisational culture plays an important role in forming a sustained competitive advantage, numerous studies about organisational culture have been completed. However, few studies have been conducted by analysing the references of publications with a visual pattern. Moreover, this subject has reached a certain degree of maturity; hence, a review that analyses the trends of organisational culture is urgent.

Aim: The aim of this study was to provide broad information on organisational culture, including authors, journals, countries and references. In addition, the evolution of organisational culture is depicted and potential future research focuses are predicted.

Setting: Using the Web of Science as a data source, we captured 1479 publications in science citation index (SCI) and social science citation index (SSCI) from 2005 to 2016 with 63682 corresponding references for analysis.

Methods: A bibliometric approach using CiteSpace software was applied to quantitatively and visually analyse organisational culture.

Results: (1) The USA is the most productive country followed by the UK and then Australia in terms of publication; (2) scholars are mainly focused on 'performance', 'innovation' and 'knowledge management' aspects; (3) most fundamental theories and frameworks were created from the 1980s to the 1990s; (4) the Journal of Business Ethics is the most appropriate journal for contributions, whereas the Academy of Management Review is suitable for scholars to do a literature review, construct a theoretical framework and develop a research design; and (5) future research on this field has been justified accordingly.

Conclusion: These findings not only provide basic background knowledge about organisational culture for new researchers but also provide a framework for visual and quantitative research to management scholars and fill the gap between organisational culture and bibliometric analysis.

\section{Introduction}

Thirty-five years ago, a focus on the enterprise competition model of the USA and Japan arose, which led to fervent research and even a revolution in management concepts, eventually resulting in a new management trend called 'organisational culture'. The USA had been a global leader in management theories and institutional research in the field with the classic rational management style of the 1970s and 1980s until the US economic recession; in the meantime, the prominence of the Japanese economy challenged the USA and even all Western countries (Pascale \& Athos 1982). So, the mechanisms of organisational management that compelled opposite developmental roads in American and Japanese economies became a concern for American managerial scholars and corporate managers. Pascale and Athos (1982) found the crucial elements generating this difference between American and Japanese companies in their study of Japanese management. Apart from the rigid management methods and institutions of the classic American style, Japanese companies paid more attention to flexible spiritual factors and long-term collective value (Pascale \& Athos 1982). Meanwhile, Japanese companies established organisational cultures that facilitated business innovations and also integrated value and psychological factors. In general, the success of Japanese companies in organisational performance and competitive advantage surpassed even the USA (Pascale \& Athos 1982). This trend highlighted the significance of organisational culture, called for the re-examining of corporate soft factors and also emphasised the influence of soft factors on corporate development. Nowadays, organisational culture is treated as the key factor for business success and it has been empirically verified to promote organisational effectiveness (Gregory et al. 2009), organisational innovation (Hogan \& Coote 2013), organisational identity (Ravasi \& Schultz 2006) and organisational performance (Gregory et al. 2009). 
Currently, organisational culture is thought to be a crucial factor associated with innovation in business success, especially in the context of the knowledge economy (Büschgens, Bausch \& Balkin 2013). Although organisational culture has been well studied and has become a mature branch of management science, few studies have been conducted in this field using quantitative and visualised bibliometrics to analyse references instead of original papers. Hence, we use a quantitative method instead of the traditional citation counts and personal, qualitative, narrative-based method to obtain a more comprehensive understanding of the evolution and development of organisational culture. Moreover, organisational culture has reached a certain degree of maturity, where it is now treated as an exclusive field of study; therefore, identifying new potential future trends is urgent. As organisational culture in practice and academia has become so significant, a deep analysis of the implications, hot topics and research directions of this term is necessary. This paper uses a bibliometrics method through CiteSpace to provide an overview of the studies in the organisational culture field. Apart from the historical development of organisational culture in the next section, growth trends, core authors, top journals, countries, institutions and important reference articles are shown. Based on these results, future trends are predicted. Altogether, this paper not only supplies basic background knowledge about organisational culture for new researchers but also provides a framework of visual and quantitative research for management scholars and fills the gap between organisational culture and bibliometric analysis. In addition, compared to other methods of research in this field, such as systematic literature review and metaanalytic review, our study has three advantages over others. Firstly, the results displayed in tables and figures are easier for researchers to understand. Secondly, CiteSpace provides broad analytic information, such as author, institution, country and reference, rather than just analysing the contents of publications on organisational culture. Thirdly, potential future trends do not focus on just one aspect through statistical analysis, which may help researchers in different areas to extend their research and help practitioners understand whether their business challenge is related to organisational culture.

This paper begins with a brief overview of the development of organisational culture and is then followed by the information about the tool used for the analysis (CiteSpace) and the searching procedure. Next, the results of citing papers (i.e. papers searched in this study) and cited papers (i.e. references of searched papers in this study) are displayed. The last section of this paper concludes with the findings in the research, represents practical and methodological contributions, and demonstrates some limitations.

\section{Theory and literature}

The concept of organisational culture was initiated in cultural anthropology and has been widely applied in the study of organisational behaviours, management and marketing (Gregory et al. 2009; Schein 1992). Organisational culture is defined as a set of values, beliefs, assumptions and symbols that is shared by all members and that directs their decisions and organisational behaviours (Schein 1985). Although this term appeared in the early 1970s, it was not analysed or adopted by management scholars until the 1980s (Hatch 1993). Because of diversity of the researchers' backgrounds and the notability of this popular topic in management, hundreds of definitions were constructed. Organisational culture could refer to, for instance, group norm (Kilmann, Saxton \& Serpa 1987), organisational climate (Schneider, Brief \& Guzzo 1996), ideology (Goll \& Sanbharya 1990), shared beliefs (Lorsch 1985), mental mode (Hofstede 1998), basic assumptions (Schein 1985), organisational strategies (Weich 1985) and organisational symbols (Pettigrew 1979). In the early 1980s, four masterpieces associated with organisational culture made waves in management academia in the USA: Theory Z by Ouchi (1981), Corporate Culture by Deal and Kennedy (1982), The Art of Japanese Management by Pascale and Athos (1982) and In Search of Excellence by Peters and Waterman (1984). These four publications enlightened organisational culture and pushed it towards a higher theoretical and practical level.

In the 1980s, academics were mainly focusing on the definition, connotation, structural elements and type classification of organisational culture, and most of these studies were qualitative. Even though the definitions and connotations of organisational culture could not reach a consensus at that time, Schein's idea and theory were representative ones in academia to some extent. Schein (1992) shaped organisational culture in his book Organisational Culture and Leadership. He explained it as the norms of expected behaviour that employees would follow, provided by organisational values and beliefs; moreover, it was a very important and invisible social force. The original text of Schein's (2004) book defined organisational culture as:

... the pattern of basic assumptions that a given group has invented, discovered, or developed in learning to cope with its problems of external adaptation and internal integration, and that have worked well enough to be considered valid, and therefore, to be taught to new members as the correct way to perceive, think, and feel in relation to these problems. (p. 17)

According to Schein's (1985) model of organisational culture, three layers of culture were constructed, which were artefacts, values and basic assumptions from outer to inner levels. Further, Schein (2004) investigated these three levels by the degree of visibility to observers. Schein's (1985) model of organisational culture made him particularly influential, as he articulated and provided a qualitative framework for analysing and intervening in culture management fields. There was no doubt that Schein laid the basis for organisational culture models and qualitative research, and he believed that it was the subconscious that formed the most invisible layer, which would make it difficult to measure; hence, organisational culture investigations should mainly depend on qualitative research. 
However, in the 1990s, quantitative studies gradually permeated this new management field despite many still agreeing with Schein's idea that quantitative investigations made no contribution to the understanding of culture at a deep level. Scholars constructed a quantitative index system from diversified dimensions that could better interpret the relationship between organisational culture and corporate outputs, such as business performance (O'Reilly et al. 2014), employee satisfaction (Gillespie et al. 2008) and innovation ability (Tellis, Prabhu \& Chandy 2013). Quantitative studies of organisational culture from O'Reilly, Chatman and Caldwell (1991), Hofstede (1998), Cameron and Quinn (1998) and Denison and Mishra (1995) were typically representative. O'Reilly et al. (1991) used the Q-sort method on 54 value indicators acquired from the existing literature to develop an 'organisational culture profile' (OCP). Seven dimensions, which were innovation, outcome orientation, respect for people, team orientation, stability, aggressiveness and attention to detail, and 54 items were covered in the OCP scale to measure the fitness of person-organisation (O'Reilly et al. 1991). Hofstede (1998) was the academic authority on cross-culture management, and he proposed the Multidimensional Model of Organisational Culture, which consists of the following scales: process oriented to results oriented, employee oriented to job oriented, parochial to professional, open system to closed system, loose control to tight control and normative to pragmatic. The Competing Values Framework (CVF) was built by Quinn and Spreitzer (1991) as a two-dimensional framework in which the dimensions were structure and focus. These two dimensions separated organisational culture into four types, flexible external focus, control external focus, flexible internal focus and control internal focus, represented by adhocracy, market, clan and hierarchy types, respectively. Recently, Kokt and Merwe (2011) have applied CVF as a quantitatively diagnostic tool in a leading private security company to investigate the organisational culture type; furthermore, according to the statistical results, they have offered some recommendations to balance the organisational culture orientations to help corporate future development. Based on CVF, the Organisational Culture Assessment Instrument (OCAI) was published by Cameron and Quinn (1998). This instrument contains six dimensions that are dominant characteristics, organisational leadership, management of employees, organisational glue, strategic emphases and criteria of success (Cameron \& Quinn 1998). The 'Denison Organisational Culture Survey' (DOCS) was also based on CVF; however, using grounded theory on five organisations and Chief Executive Officers from 764 organisations as samples, Denison constructed a 'Theoretical Model of Culture Traits' (TMCT). Akin to CVF, TMCT contains four cultural traits: adaptability, mission, consistency and involvement (Denison \& Mishra 1995); additionally, each trait includes three sub-dimensions to make a total of 12 dimensions (Fey \& Denison 2003).

Organisational culture could be a source of sustained competitive advantage (Barney 1986), and a large number of empirical research about organisational facilitation of employee retention (Sheridan 1992), knowledge management (Alavi \& Leidner 2006), effectiveness (Denison \& Mishra 1995; Fey \& Denison 2003; Gregory et al. 2009), innovation (Büschgens et al. 2013), creative output (Kessel, Oerlemans \& Stroe-Biezen 2014) and performance (Hogan \& Coote 2013) were mainly documented. Barney claimed that to achieve these beneficial attributes in terms of sustained competitive advantages, organisational culture must meet three conditions: be valuable, rare and difficult to imitate (Barney 1986). Several important functions of organisational culture were identified. Firstly, organisational culture can serve as a source of distinctions among organisations and can transmit a perception of identity for organisation members (Ravasi \& Schultz 2006). Secondly, it can promote the generation of commitment (Peters \& Waterman 1984). Thirdly, it can strengthen the stability and consistency of the organisation (Louis 1980). Finally, it can manage the behaviours of the members of the organisation by shaping their shared values and beliefs (Schein 1992). Hence, a large amount of empirical evidence suggests that there are positive correlations between organisational culture and market performance (Homburg \& Pflesser 2000), financial performance (Homburg \& Pflesser 2000), employee attitudes (Gregory et al. 2009), knowledge management and organisational effectiveness (Zheng, Yang \& Mclean 2010). Because organisational culture has some specific characteristics such as being mostly invisible and hard to quantify, as well as creativity or uniqueness, and because of the width and depth of the research perspectives, there is no doubt that quantitative research cannot substitute for qualitative research. Therefore, we believe that the integration of both methods can foster high-level achievements.

\section{Methodology and data}

Bibliometrics is a statistical analysis of extant literature and is used to provide quantitative analysis of publications in a given field (Mayr \& Scharnhorst 2014). The main categories of information analysed with respect to bibliometrics are the authors, keywords, references, journals, countries, institutions and the trends in a special field (Abramo, D'Angelo \& Viel 2011). Bibliometrics originated from the quantitative research of literature that emerged in the early 1900s, and since then literature analysis based on bibliometrics has been widely applied in academic research (Diem \& Wolter 2013). Graphical research and visualisation studies of bibliometrics can be managed with the help of computer technology. Ma and Xi (1992) emphasised that graphical visualisation studies based on co-citation analysis could provide more information and make data more comprehensive. Additionally, this method could help researchers determine the most recent developments in a special field and forecast the possible direction of such a field (Chen 2006). Co-citation analysis considers that any new theory comes from an existing one, and two articles are defined as having a co-citation relationship if they are cited by one or more articles at the same time; to what extent they are close to each other is called the co-citation degree, which is calculated by the number of citations (Small 2003). 
CiteSpace is a free Java-based application for analysing cocitations and generating visual maps, as well as finding trends and patterns. This powerful and popular tool is designed for finding critical points in the development and evolution of a field, especially turning points and pivotal points. It provides various functions to help with identifying fast-growing topical areas, finding citation hot spots, decomposing a network into clusters, automatically labelling clusters with keywords from citing articles, finding geospatial patterns of collaboration and unique areas of collaboration and so forth (Chen 2006). In building the network image, three types of views - cluster view, timeline view and timezone view - can be used for analysing different information including knowledge structure, time span of a topic and evolution trends, respectively. The primary source of input data for CiteSpace is the Web of Science (Chen 2013).

This paper uses CiteSpace version V and Java VIII as a visual and analytic research tool that is freely available online and was founded by Chaomei Chen, the inventor of CiteSpace (http://cluster.cis.drexel.edu/ cchen/citespace/). The Web of Science is one of the most excellent literature databases containing citation information sources crucial for this study (Chen et al. 2016). Hence, it was used as a data resource website and was also recommended by CiteSpace. To obtain the original target articles' information, 'organisational culture' and 'corporate culture' were used as a whole phrase in the topic search. Several restrictions were set before the topic search. Firstly, the Web of Science Core Collection was used rather than All Databases so that articles would be of high quality and influential in this field. Secondly, the time span was set from 2005 to 2016 because some core journals associated with organisational culture in social science were collected from 2005, such as Academy of Management Journal, Academy of Management Review, Organisation Science and so on. Thirdly, the Science Citation Index Expanded (SCIEXPANDED) and Social Sciences Citation Index (SSCI) were used as citation indexes to make the samples more comprehensive. Finally, 3488 articles were selected from the database, and 'management', 'business' and 'psychology applied' were set as the categories for further restriction to refine the sample size to 1479 , limiting the sample to the main discipline and the nature of 'organisational culture'. Even though Web of Science does not include all papers about organisational science, the references from collected records cover almost every important article in this field; therefore,

TABLE 1: Summary of search details.

\begin{tabular}{ll}
\hline List & Details \\
\hline Analysis software & CiteSpace \\
Source website & Web of Science \\
Database & $\begin{array}{l}\text { SCI-EXPANDED, SSCI (Science } \\
\text { collection) }\end{array}$ \\
Years & $\begin{array}{l}\text { 2005-2016 (12 years) } \\
\text { Categories }\end{array}$ \\
Management, Business, Psychology \\
Applied
\end{tabular}

SCI-EXPANDED, Science Citation Index Expanded; SSCl, social science citation index. crucial points can be highlighted on the map of cited reference, author or institution. The search details are listed in Table 1.

\section{Results and discussion of citing papers analysis Document information}

Journal articles were identified as the most common document type, which accounts for $90.96 \%(N=1318)$ of all papers in this study, followed by reviews $(N=82)$. Almost all papers were published in English $(N=1454)$ as the database of SCI-Expanded and SSCI mostly consists of English journals rather than journals in other languages, and scholars tend to publish their articles in English as they want them to be widely accepted.

There is an obvious sudden increase in publications in this field, from 75 articles in 2007 to 118 articles in 2008, and the number of articles continued to increase until peaking at 163 articles in 2012, followed by a decrease to approximately 130 articles in subsequent years (shown in Figure 1). The doubling in the number of articles published from 2007 to 2012 illustrates that organisational culture has still been an active topic in recent years; however, it does not mean that research in this field is hot or is increasing compared to other bibliography studies, such as 'emergy' research increasing from 5 articles in 1993 to 93 articles in 2014 (Chen et al. 2016). The 1479 papers in this study have been cited 19982 times, and the steady linear pattern of growth rate shown in Figure 2 for each year also proves that research in organisational culture reached a plateau at approximately 130 articles each year and will probably remain the same in the future. Nevertheless, it is now a mature subject, and there are still many works (130 articles per year) on this topic compared to other studies (Chen et al. 2016; Feng et al. 2015). Unfortunately, a clear pattern from 1970 to 2004 cannot be captured through Web of Science because of the collection deficiency; however, this shortcoming does not affect our results in the subsequent analysis, and the 1479 articles' references cover almost every important article in this field for this study.

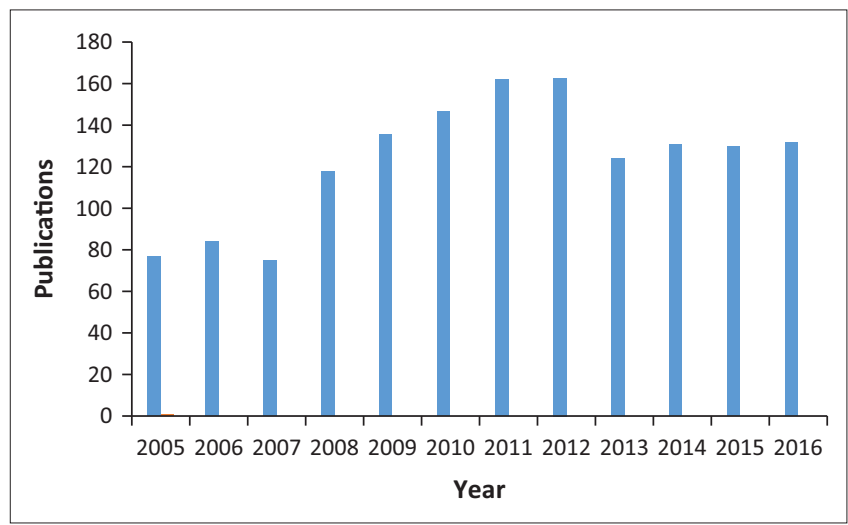

FIGURE 1: Number of publications on organisational culture for each year from 2005 to 2016 in the Web of Science. 


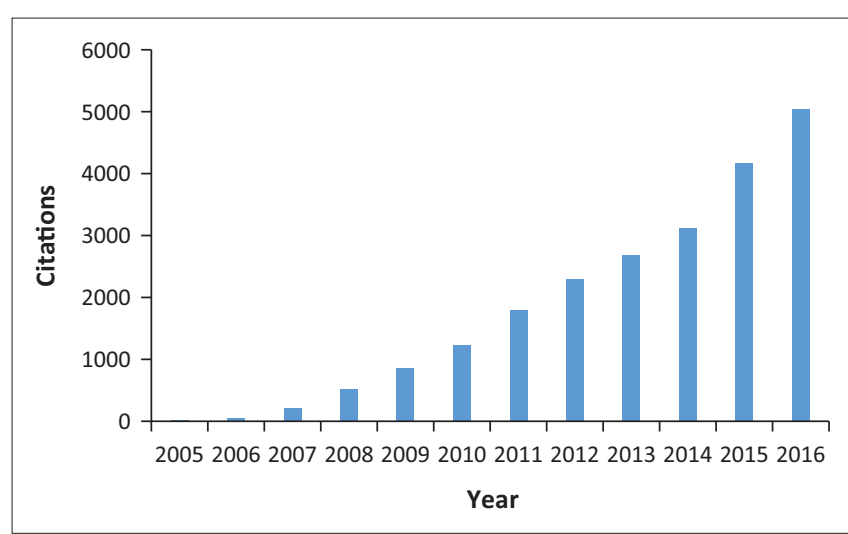

FIGURE 2: Number of citations about organisational culture for each year from 2005 to 2016 in the Web of Science.

\section{Authorship}

Based on the database from 2005 to 2016, there are 2557 authors contributing to 1479 articles. The top 27 most active authors, with more than 3 articles each, are listed in Table 2. The number of publications for the top 27 authors is relatively small and disperse, and only accounts for $8.42 \%$ of the 1479 articles; however, some cooperative pattern can be seen among these top authors in Figure 3. Nine collaborative groups can be found, which are presented by nodes linked by lines. The size of the nodes represents the number of articles, whereas the lines represent the collaborative relationship. All four papers from Flatten (Brettel, Chomik \& Flatten 2015; Engelen et al. 2014; Strese et al. 2013, 2015) are associated with the top-ranked scholar Brettle, and they mainly focused on how organisational culture and innovation culture could influence new product developmental performance, in other words, how culture impacts innovation. Engelen (2010) was investigating the effect of organisational culture, especially cross-national culture, on entrepreneurial orientation or innovation orientation; therefore, the key point that these three scholars captured was the relationship between innovative performance and cross-national organisational culture (Engelen et al. 2014). Studies by Ogbonna and Harris (2007) dealt with various topics such as websites, the Internet and organisational behaviours; however, they emphasised that organisational culture played a key role in the operation of an organisation (e.g. Harris \& Ogbonna 2007; Lloyd \& Ogbonna 2011; Ogbonna \& Harris 2007, 2014). Baruch and He highlighted the importance of organisational culture in organisational learning and organisational identity (e.g. He \& Baruch 2009; Hong et al. 2016). Eddleston and Kellermanns (e.g. Eddleston, Kellermanns \& Sarathy 2008; Eddleston, Kellermanns \& Floyd 2013; Kellermanns et al. 2012) were also studying how organisational culture affects innovative performance, but in family firms. Chatman and Caldwell (e.g. Chatman et al. 2014; O'Reilly et al. 2014) claimed that organisational culture had a positive empirical effect on firm performance in their studies. The relationship between firm performance and organisational culture was further improved by Denison and Gillespie (e.g. Boyce et al. 2015; Kotrba et al. 2012). Huhtala and Feldt discussed organisational culture from an ethical aspect and highlighted the perceptions of ethical
TABLE 2: The top 27 most productive authors.

\begin{tabular}{lccc}
\hline Author & Total publications & Author & Total publications \\
\hline Brettle M & 7 & Gillespie M A & 4 \\
Ogbonna E & 7 & Howard-Grenville J & 4 \\
Baruch Y & 6 & Huhtala M & 4 \\
Harris L C & 6 & Islam G & 4 \\
Blanck P & 5 & Kellermanns F W & 4 \\
Chatman J A & 5 & Menguc B & 4 \\
Eddleston K A & 5 & Mills J H & 4 \\
Wei L Q & 5 & Mueller J & 4 \\
Auh S & 4 & Narasimhan R & 4 \\
Baird K & 4 & O'Reilly C A & 4 \\
Cavusgil S T & 4 & Slater S F & 4 \\
Engelen A & 4 & Teerikangas S & 4 \\
Feldt T & 4 & Yilmaz C & 4 \\
Flatten TC & 4 & - & - \\
\hline
\end{tabular}

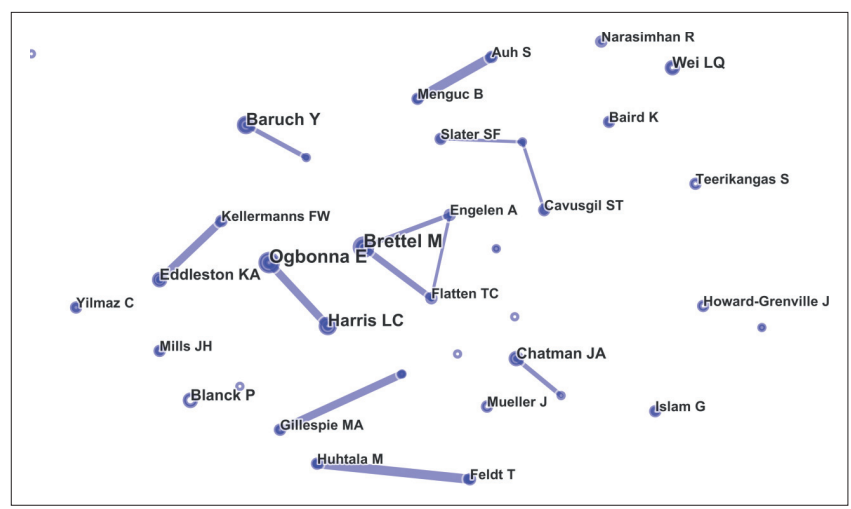

FIGURE 3: Map of the most productive authors with collaborative links.

organisational culture affecting management style and the well-being of leaders (e.g. Huhtala et al. 2015a; Huhtala, Kaptein \& Feldt 2015b; Kangas et al. 2014; Lamsa et al. 2013). Menguc and Auh depicted the function of organisational culture and leadership in marketing (e.g. Menguc \& Auh 2008a, 2008b, 2010; Menguc, Auh \& Shih 2007), whereas Hult, Slater and Cavusgil discussed the impacts of crossnational culture on market orientation and cooperation (Kirca, Cavusgil \& Hult 2009; Slater, Hult \& Olson 2010). Considering the relationship between organisational culture and the various aspects that the top productive authors focused on, it could be predicted that these topics, such as innovation, firm performance and market orientation, might be continually explored in the future.

\section{Journals}

The number of organisational culture articles in the top 10 journals is displayed in Table 3. Obviously, most of these journals are in management and business fields, and one, Human Relations, is correlated to the fields of psychology and sociology. The publishing trends of these journals were analysed through Web of Science. The top journal Journal of Business Ethics showed a downtrend in article publications with respect to organisational culture, whereas the Journal of Business Research and the African Journal of Business Management showed an uptrend. In summary, the information in this section provides a general view that scholars from certain categories are more suitable for organisational culture 
TABLE 3: The top 10 journals for organisational culture publications.

\begin{tabular}{lc}
\hline Journal & Total publication \\
\hline Journal of Business Ethics & 83 \\
International Journal of Human Resource Management & 48 \\
Journal of Organisational Change Management & 47 \\
Journal of Business Research & 37 \\
Management Decision & 32 \\
African Journal of Business Management & 31 \\
Human Relations & 30 \\
Journal of Knowledge Management & 27 \\
Industrial Marketing Management & 25 \\
Cross Cultural Management: An International Journal & 21 \\
\hline
\end{tabular}

TABLE 4: The top 10 countries for organisational culture publications.

\begin{tabular}{lc}
\hline Country & Total publication \\
\hline USA & 524 \\
England & 172 \\
Australia & 104 \\
China & 85 \\
Canada & 80 \\
Spain & 74 \\
Germany & 67 \\
Netherlands & 54 \\
Taiwan & 46 \\
France & 39
\end{tabular}

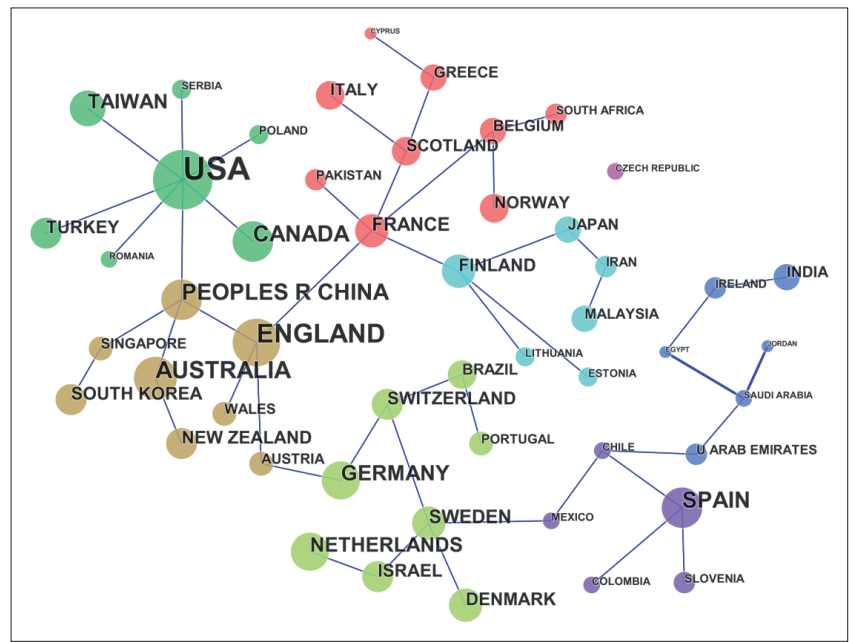

FIGURE 4: Cluster map of productive countries or territories.

investigations and directs new researchers to journals that are better choices for article submission.

\section{Countries and institutions}

There are 77 countries contributing the 1479 articles in this study, and the top 10 most productive countries producing $85.92 \%$ of all articles are listed in Table 4 . There is no doubt that the USA, as the place of origin, contributes the most and accounts for one-third of the total articles. Most of these countries or territories are developed except for China; however, it should be noted that the rate of economic growth in China has been high since 1990 (Wan, Morgan \& Barro 2016). Additionally, the introduction of the idea of organisational culture to China occurred in the 1990s (Tsui, Wang \& Xin 2016); therefore, there may be a potential relationship between economic growth and the practical
TABLE 5: Analysis of cluster information by country.

\begin{tabular}{ll}
\hline Cluster & \multicolumn{1}{c}{ Keyword } \\
\hline USA & Customer orientation \\
People's Republic of China, England and Austria & Local government \\
France & Subculture \\
Finland & Cooperation \\
Germany and Sweden & Deep level diversity \\
Mexico and Chile & Team innovation \\
Saudi Arabia & Knowledge management \\
\hline
\end{tabular}

TABLE 6: The top 13 institutions for organisational culture publications.

\begin{tabular}{|c|c|c|}
\hline Institution & Publication & Research focus \\
\hline Michigan State University & 16 & $\begin{array}{l}\text { Innovation, performance, marketing, } \\
\text { supply chain }\end{array}$ \\
\hline Arizona State University & 15 & Leadership, decision, performance \\
\hline Northeastern University & 14 & Leadership, innovation, performance \\
\hline Vrije University Amsterdam & 14 & Performance, knowledge sharing \\
\hline University of Illinois & 13 & Leadership, knowledge sharing \\
\hline University of North Carolina & 13 & Performance, knowledge sharing \\
\hline Texas A\&M University & 12 & Performance, knowledge sharing \\
\hline University of Minnesota & 11 & Innovation, performance \\
\hline University of Queensland & 11 & $\begin{array}{l}\text { Innovation, performance, knowledge } \\
\text { sharing }\end{array}$ \\
\hline Brunel University & 11 & Organisational identity, performance \\
\hline Rutgers State University & 11 & Performance, HR management \\
\hline University of Wisconsin & 11 & Organisational identity, HR management \\
\hline $\begin{array}{l}\text { Queensland University } \\
\text { of Tech }\end{array}$ & 11 & $\begin{array}{l}\text { Innovation, performance, knowledge } \\
\text { sharing }\end{array}$ \\
\hline
\end{tabular}

significance of organisational culture. Moreover, much of the literature associated with organisational culture is linked with innovation, which could lead to the success of companies and even countries.

Collaborative patterns have been analysed by CiteSpace, and the image shows that almost all countries have a cooperative relationship with the USA and England. In Figure 4, each node represents a country, and nodes with the same colour are grouped as a cluster, implying a special and major research focus. A country linked with another cluster is involved in another focus with partial attention. Cluster information is displayed in Table 5 and named by the countries associated with neighbouring clusters; moreover, the research focuses are labelled by the keywords of the articles. It can be observed that several countries tend to work together for a major cluster and that each cluster usually has one or two core countries depending on the size of the node.

It is easy to determine the top-level research groups of organisational culture worldwide through institutional analysis by CiteSpace. More than 1000 institutions are identified in 1479 articles. To make the results comprehensive, the most important institutions were used for analysing the research direction (more than 10 articles) and the cooperative patterns (more than seven articles). As shown in Table 6, Michigan State University ranked first with 16 publications, followed by Arizona State University with 15 publications and Northeastern University with 14 publications. The top three institutions are all from the USA, and it should be noted that 10 out of 13 institutions are from the USA, 2 from 


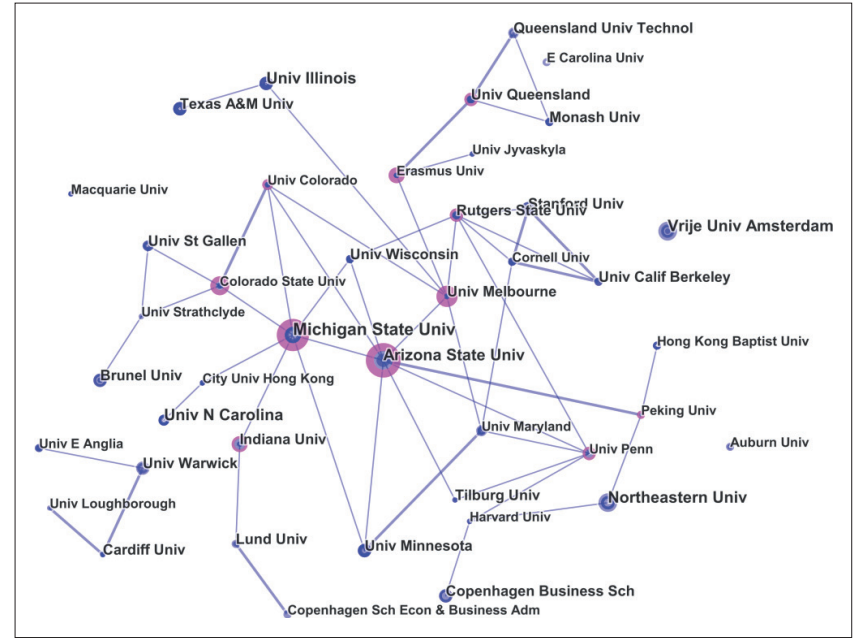

FIGURE 5: Map of the most productive institutions with collaborative links.

TABLE 7: The top 20 keywords from publications.

\begin{tabular}{lccc}
\hline Keyword & Abbreviation & Frequency & Centrality \\
\hline Organisational Culture & OC & 1003 & 0.28 \\
Performance & $\mathrm{Pe}$ & 484 & 0.28 \\
Management & $\mathrm{Ma}$ & 204 & 0.11 \\
Innovation & $\mathrm{In}$ & 140 & 0.03 \\
Knowledge management & $\mathrm{KM}$ & 124 & 0.03 \\
Strategy & $\mathrm{St}$ & 111 & 0.08 \\
Leadership & $\mathrm{Le}$ & 106 & 0.02 \\
Market orientation & $\mathrm{MO}$ & 102 & 0.03 \\
Behaviour & $\mathrm{Be}$ & 99 & 0.01 \\
Capability & $\mathrm{Ca}$ & 85 & 0.02 \\
Competitive advantage & $\mathrm{CA}$ & 85 & 0.06 \\
Commitment & $\mathrm{Co}$ & 75 & 0.03 \\
Human Resource & $\mathrm{HR}$ & 75 & 0 \\
management & & & \\
Business & $\mathrm{Bu}$ & 68 & 0 \\
National culture & $\mathrm{Nc}$ & 66 & 0.02 \\
Job satisfaction & $\mathrm{JS}$ & 65 & 0 \\
Framework & $\mathrm{Fr}$ & 58 & 0.01 \\
Trust & $\mathrm{Tr}$ & 56 & 0.01 \\
Technology & $\mathrm{Te}$ & 55 & 0 \\
Orientation & $\mathrm{Or}$ & 53 & 0.03 \\
\hline & & &
\end{tabular}

Australia and 1 from the UK. It can also be observed from Figure 5 that American institutions are more important and are widely linked through the network. The research directions are not obviously separated, and they are mainly associated with performance, innovation and knowledge sharing. Important institutions are displayed with purple rings. Arizona State University is the core institution in the network and two central institutions are linked to Arizona State University. It can also be observed that Arizona State University holds the centre position in the network, connecting with the most institutions.

\section{Keywords}

The top 20 keywords are listed in Table 7, and two modifications were applied to ensure the comprehensiveness of the keyword information. Firstly, keywords with the same meaning were combined, such as organisational culture and corporate culture. Secondly, keywords that were not associated with the research directions such as firm, model,

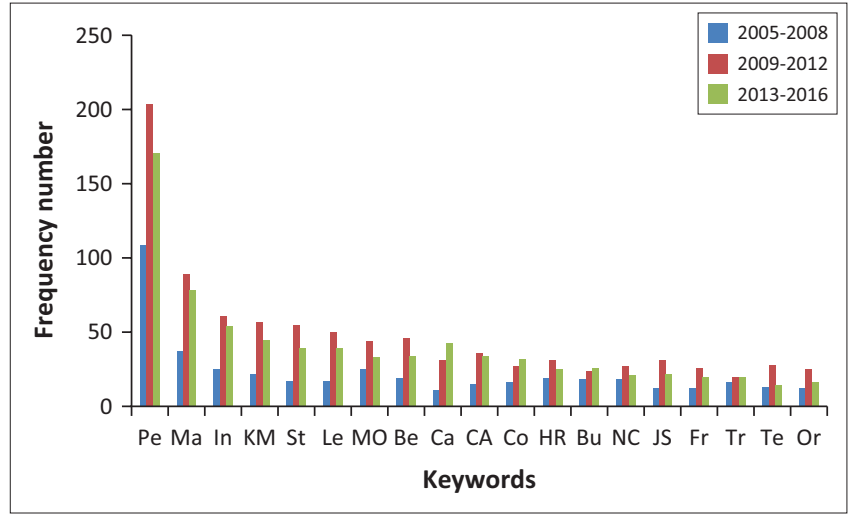

FIGURE 6: The frequency of the top 20 keywords from publications (excluding organisational culture) in three time periods.

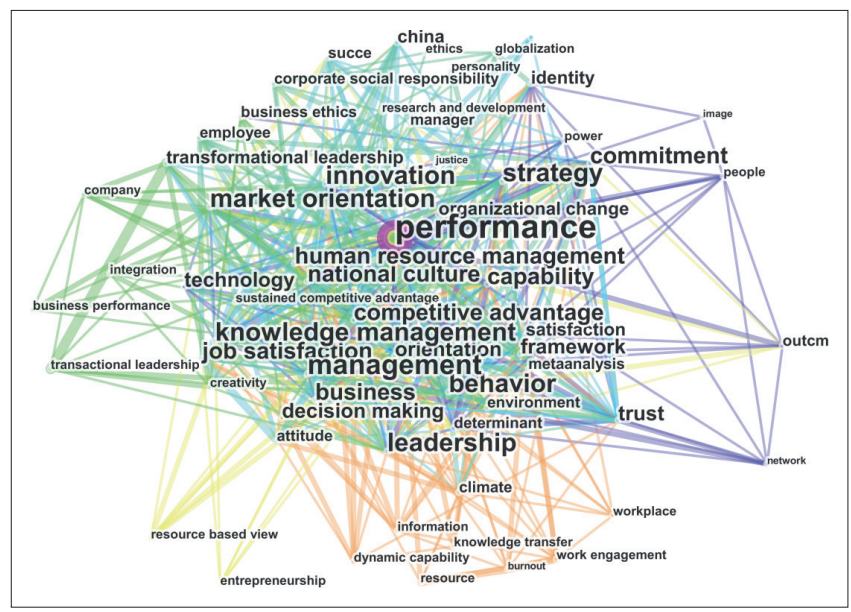

FIGURE 7: The map of keywords in co-citation relationship.

value and so on were put into the exclusive list. Apart from the topic words 'organisational culture', the most emerging word is 'performance', followed by 'management', and 'innovation'; this rank remains the same from 2005 to 2016 and can be seen in Figure 6. To view the trends in organisational culture studies, 12 years, from 2005 to 2016, were divided into three time periods: 2005-2008, 2009-2012 and 2013-2016. The top 3 keywords remain at the same rank, which indicates that performance, management and innovation are all closest to the topic. The rank for other keywords is roughly the same with some mild perversion. Despite some of these words being above the top 20 in different periods, they do not exceed the top 30. From the result, it can be concluded that this field is mature in organisational discipline and that there are not any new branches that form another direction apart from the extant ones. Hence, it is predicted that the research trend will be relatively stable in the future, focusing on 'performance', 'management' and 'innovation'; however, to detect tiny changes or a small propensity for topics to shift along with time, the keywords co-citation is used for the analysis shown in Figure 7. The whole 12-year period is divided into six equal slices, and the top 30 keywords from each slice are extracted to form the keywords co-citation network. Then, the keywords with different colours, which represent the first year that they were co-cited, are linked through their cocitation relationship. The cold colour stands for early years, 
whereas the warm colour is for recent years. As the field of organisational culture progress is relatively mature, the pattern seems intricate and crowded together without obvious branches. Therefore, nodes with the same colour links were pulled to the edge of the network manually and laid anticlockwise from cold colour to warm colour, and the nodes with links throughout the network remained in the centre. Performance is still the pivotal point penetrating into all the topics, and at the bottom of Figure 7, several keywords are connected in recent years. Therefore, the topics of knowledge transfer, work engagement and dynamic capability are assumed to be more important or to form a new branch in the near future. Additionally, we have applied burst detection to search for the words trending upwards in recent years. Apart from 'dynamic capability', 'decision making' is identified as another burst keyword from 2013 until now, and it may become a future hot topic.

\section{Results and discussion of cited papers analysis Reference articles}

With the support of CiteSpace, 63682 references from 1479 articles were analysed. The top 10 reference articles according to their citation frequency are listed in Table 8. Books from Hofstede (1980) and Schein (1985) are both ranked first, followed by O'Reilly et al.'s (1991) work. Among the top 10 reference articles, three articles belong to Hofstede and two are from Schein; therefore, it can be assumed that Hofstede and Schein are the base founders of the organisational culture field and that their works play an important role in the development of organisational culture.

It is evident that Hofstede focuses more on quantitative research, whereas Schein focuses on qualitative research; moreover, most of Hofstede's studies (e.g. Hofstede 1980, 1998, 2001) tend to investigate the cultural differences of cross-national or cross-organisational culture, whereas Schein's studies (e.g. Schein 1985, 1992, 2004) tend to analyse the deep levels of organisational culture within an organisation, such as how it is formed and how it works. Culture's Consequences is Hofstede's (1980) best-known book, and the four dimensions of organisational culture he proposed, 'Individualism', 'Power Distance', 'Uncertainty Avoidance' and 'Masculinity', have become a milestone in cross-national quantitative culture research and help in

TABLE 8: The top 10 references in this paper.

\begin{tabular}{lll}
\hline Reference article & Frequency & Type of source \\
\hline Hofstede (1980) & 147 & Book \\
Schein (1985) & 147 & Book \\
O'Reilly et al. (1991) & 131 & Journal \\
Podsakoff et al. (2003) & 130 & Journal \\
Fornell and Larcker (1981) & 123 & Journal \\
Deshpandé et al. (1993) & 118 & Journal \\
Schein (1992) & 113 & Book \\
Hofstede (2001) & 112 & Book \\
Barney (1991) & 110 & Journal \\
Hofstede et al. (1990) & 106 & Journal \\
\hline
\end{tabular}

understanding the differences among cultures (Hofstede \& Geert 1980). Schein has defined organisational culture in his book as the norms of expected behaviours that employees would follow, provided by organisational values and beliefs. On this basis, Schein's three-level model was built up and well interpreted. Schein also gave these assumptions different dimensions, such as 'External Adaptation Issues', 'Managing Internal Integration', 'Reality and Truth', 'the Nature of Time and Space', 'Human Nature', 'Activity' and 'Relationships'. In addition, the function of the leader and the relationship among leadership members, culture building, culture embedding and evolving were described. The third most frequently cited reference is from O'Reilly et al. (1991). In O'Reilly's research, Q-sort measurement was applied to analyse organisational culture; rather than assessing the leadership, O'Reilly emphasised the behaviours of organisational members and developed an instrument for assessing person-organisation fit called the 'Organisation Culture Profile' (O’Reilly et al. 1991).

It should be noticed that the fourth most cited reference from Podsakoff et al. (2003) is recognised as a burst reference by CiteSpace analysis. Looking at Podsakoff et al.'s (2003) study, we found that instead of studying organisational culture or other associated topics, Podsakoff's work focused on the method of the research; moreover, Podsakoff (2003) summarised the potential source of common method biases to measure constructs in behavioural research and recommended methods of avoiding these biases (Podsakoff et al. 2003). This result suggests that scholars are increasingly emphasising quantitative research in the organisational culture field and methodology.

In reference to co-citation analysis, the same slice configuration as keywords was used. The top articles are displayed by nodes with large sizes and are linked through almost the whole network in Figure 8. The result of the cluster analysis is not significant and therefore is not included in this study. There are two reasons for this situation. Firstly, the organisational culture field is a well-studied and developed theme and is developed. Moreover, the structure or content of this field is interconnected such as leadership, performance, innovation, HR management, knowledge management and so on. Secondly, the studies in this field still focus on the ideas and theories built in the past; this can be observed in the timezone map in Figure 9, which shows that all of the important papers cited in our database (2005-2016) were from 2005; therefore no new theories or branches have formed after 2005. The only point after 2005 in the timezone map is regarding the relationship between organisational culture and organisational effectiveness using Spreitzer and Quinn's CVF theory (Hartnell, Ou \& Kinicki 2011). The timeline map shows that the most important studies are concentrated in a certain period between the 1980s and the 1990s, except Podsakoff's work in 2003 and Hofstede's work in 2001, which is the second edition of his work from 1980 (Hofstede 2001), and that these works will still be the basis in the near future (Figure 10). In addition, it can also be found 


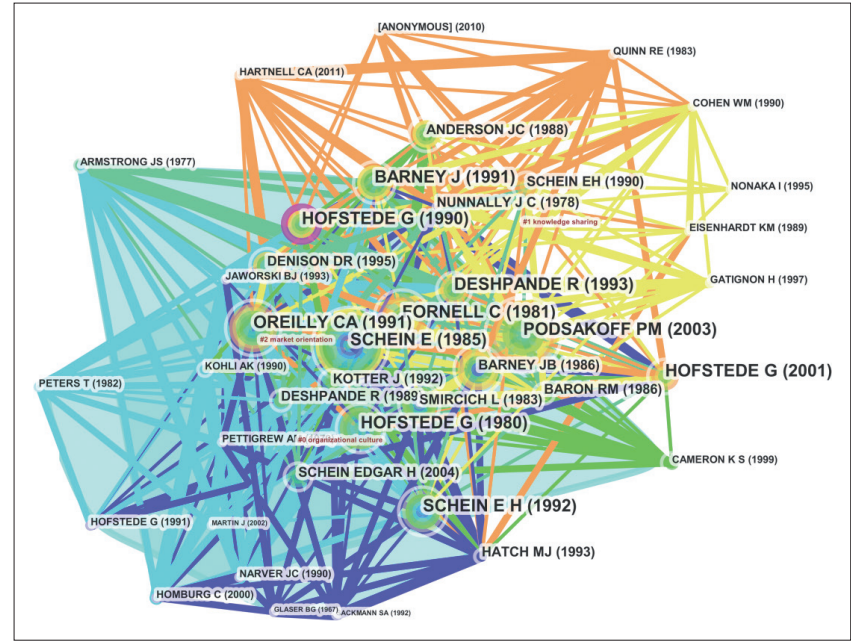

FIGURE 8: Map of references: Cluster view.

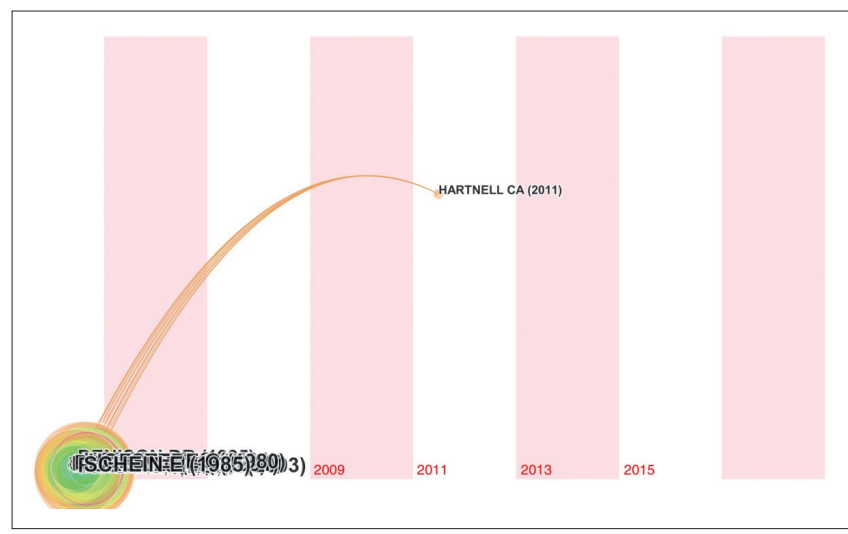

Note: All papers in the left lower corner represent the most cited articles shown in Table 8. FIGURE 9: Map of references: Timezone view.

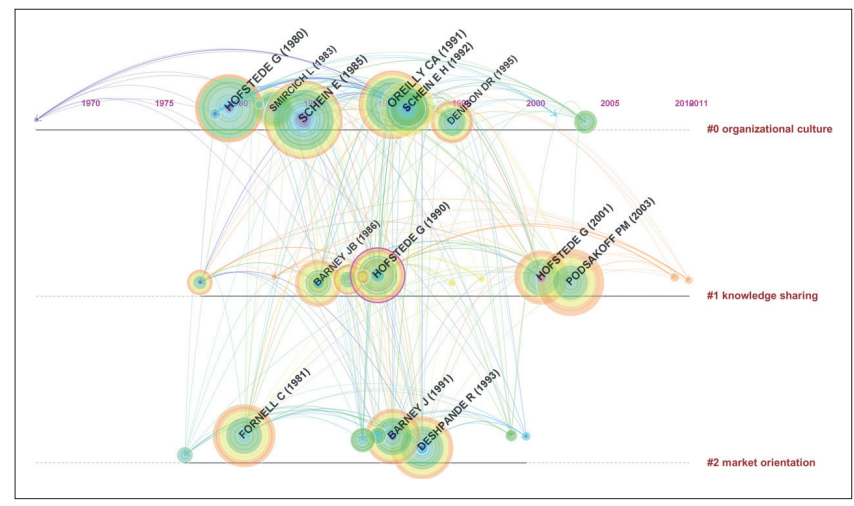

FIGURE 10: Map of references: Timeline view.

that knowledge sharing topics along with organisational culture will continue to be the focus. Because most fundamental works were conducted in the 1980s, almost all articles cite these papers for their own theoretical construction or background review, which makes the map messy. Therefore, we restricted the reference years from 2000 to 2016 rather than including all years (Figure 11). The result shows a clearly separated structure by time slice. The paper from Tellis is the most important point in Figure 11. Tellis et al. (2013) asserted that radical innovation was the key factor for

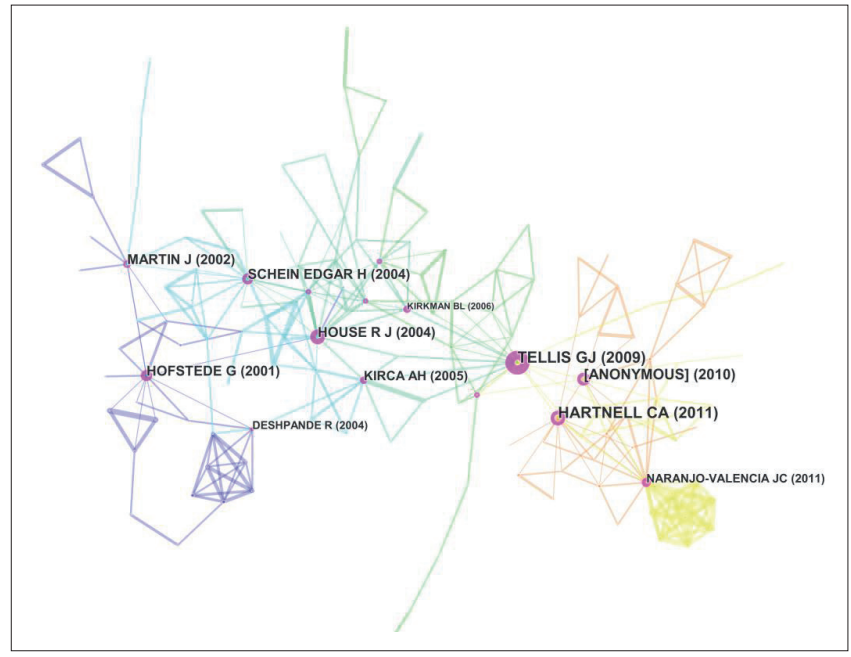

FIGURE 11: Map of references: cluster view. Restricting reference years from 2000 to 2016

TABLE 9: The Top 10 authors of reference articles.

\begin{tabular}{lcc}
\hline Author & Frequency & Centrality \\
\hline Schein Edgar H & 516 & 0.49 \\
Hofstede G & 393 & 0.2 \\
Denison D R & 219 & 0.09 \\
Barney J B & 210 & 0.29 \\
O'Reilly C A & 182 & 0.1 \\
Deshpande R & 175 & 0.08 \\
Podsakoff P M & 174 & 0.07 \\
Martin J & 152 & 0.05 \\
Eisenhardt K M & 150 & 0 \\
Fornell C & 135 & 0.07 \\
\hline
\end{tabular}

the growth, success and wealth of a company; moreover, organisational culture played a key role in innovative behaviour. It is also a turning point that links performance and innovation around 2009. As shown in Figure 11, most studies displayed on the left are associated with performance and leadership, whereas innovation-related articles are on the right, and this result is consistent with the future orientation predicted in the keywords section above.

\section{Reference authors}

The most influential authors from the 63682 references are analysed using the same slice configuration as keywords and are shown in Table 9. There is no doubt that Schein (MIT Sloan School of Management) ranks the first, since his threelevel theory of organisational culture and his well-known book Organisational Culture and Leadership were widely spread and well applied. Hofstede ranks second with 393 citations. The third most influential author is Denison; his work focused on the correlations between quantified organisational culture and dependent variables based on CVF. With Denison's organisational culture model, 4 dimensions (adaption, mission, consistency and involvement) and 12 sub-dimensions are used to measure organisational culture. Denison indicated that each of these traits had its own advantages and shortcomings. However, successful organisations are those that could resolve these contradictions without relying on simple trade-offs. 
Apart from Schein and Hofstede, Barney is another important author in the management field that has not been analysed deeply in this study. His study in 1986 about the significance of organisational culture in forming a sustained competitive advantage for a company is the 11th most cited reference after Hofstede's work, as shown in Table 8. Rather than focusing on organisational culture, Barney and Hansen (1995) searched all corporate sources associated with competitive advantages, including organisational culture. He highlighted the importance of the capabilities and behaviours of business firms operating in a market environment. Barney suggested that three types of trustworthiness (weak, semi-strong and strong) could be a source of competitive advantage. In summary, he concluded that sustained competitive advantage could not be created simply by evaluating the market environment such as with an analysis of strengths, weaknesses, opportunities and threats (SWOT) analysis; leaders must search for their unique resources and capabilities that are valuable, rare and hard to imitate (Barney 1995), for instance, organisational culture (Alavi \& Leidner 2006).

Similar to the previous reference analysis results, the most important authors in this field were from earlier years, which may imply that no author has conducted groundbreaking work in recent decades. By looking at the key nodes in Figure 12, studies from Fornell and Podsakoff have burst in recent years. Fornell focused on the drawbacks of the commonly applied chi-square test in structural equation models (SEM) with unobserved variables such as organisational culture and measurement error; in addition, he analysed and highlighted that a type II error could be substantial even though the sample size was large (Fornell \& Larcker 1981). In the end, Fornell developed a testing system based on the measures of shared variance of structural and measurement models to overcome those problems (Fornell \& Larcker 1981). Together with Podsakoff's works (e.g. Podsakoff et al. 2003), as the organisational culture field develops, more and more research not only uncovers the potential relationship between organisational culture and resources of corporate successes but also pays more attention to the methods of discovering such relationships to make the results robust and the explanations powerful.

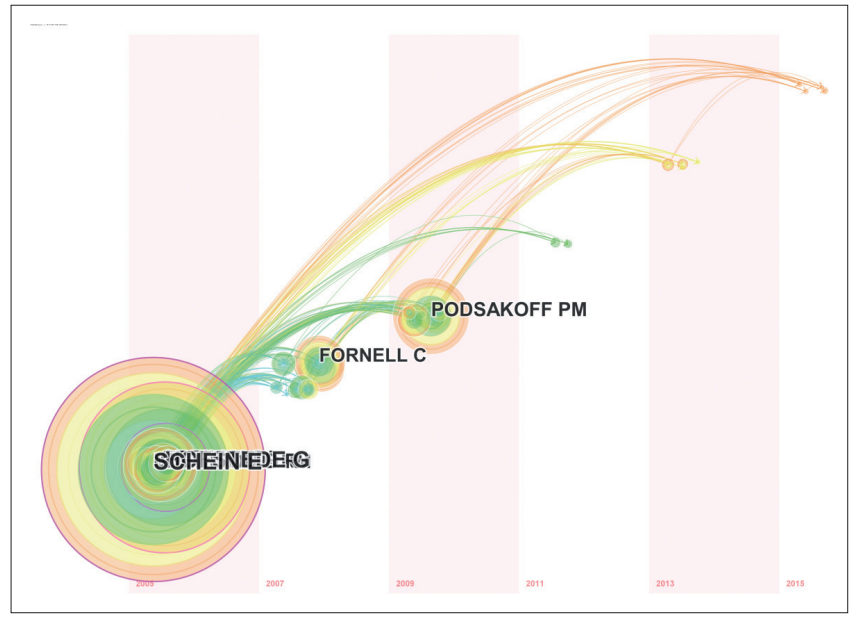

FIGURE 12: Map of reference authors: Timezone view.
TABLE 10: The Top 10 journals of the references.

\begin{tabular}{lcc}
\hline Journal & Frequency & Impact factor (2016) \\
\hline Academy of Management Review & 908 & 7.288 \\
Academy of Management Journal & 851 & 6.233 \\
Administrative Science Quarterly & 745 & 5.316 \\
Organisation Science & 597 & 3.360 \\
Journal of Management & 584 & 6.051 \\
Journal of Applied Psychology & 543 & 3.810 \\
Strategic Management Journal & 504 & 3.380 \\
Journal of Management Studies & 500 & 4.131 \\
Harvard Business Review & 474 & 2.249 \\
Human Relations & 449 & 2.619 \\
\hline
\end{tabular}

\section{Reference journals}

The top 10 cited journals with their impact factors (2016) are listed in Table 10. The Academy of Management Review is the most cited journal, with 908 citations, and it is also the toplevel journal in the management field, with an impact factor of 7.288; moreover, this journal mainly focuses on the review of basic theories and extant research, therefore providing a theoretical framework for studying organisational culture. Compared to the journals of citing papers shown in Table 3, only Human Relations exists at the same time. Human Relations is a monthly peer-reviewed academic journal covering research on business, management, organisation, sociology and psychology. It is noteworthy that this journal and the Journal of Management Studies are the only two journals from the UK, whereas the others are from the USA. Hence, it is believed that the significance of organisational culture theories is important to British scholars. However, by comparing the journals from Tables 3 and 9, reference journals are more influential than the citing journals; on one hand, it may imply that this field is relatively mature and is gradually fading from the major concerns of managerial academia. On the other hand, it may indicate that the field of organisational culture is moving towards practical applications from theoretical construction.

\section{Conclusion}

This article begins with a brief review of the developmental history of organisational culture and the core scholars with their studies and research methods. Based on 1479 publications published between 2005 and 2016, significant points emerged and a systematic overview of organisational culture was presented. We have identified the key authors, journals, countries, institutions, keywords and references, as shown in the tables and figures above. Furthermore, we have predicted that knowledge transfer, work engagement, dynamic capability and decision making may become future research focuses for organisational culture research.

This paper has shown a method supported by CiteSpace for deeply and quantitatively investigating an interesting topic. In some ways, this paper can be considered as a demonstration for studying a new field briefly and quickly. In this case, organisational culture was used as an example, which provides a methodological contribution. Compared to simply reviewing extant literature, this method not only shows the 
development of a subject, important authors and critical papers visually but also provides future trends of this subject. Furthermore, reference analysis by CiteSpace can overcome a lack of literature reading, because even though the reviewed literature is limited, their references contain enough information about the key papers in a field; hence, it directs further suitable papers to review.

To avoid misunderstanding and to guide future investigations, three main limitations of this study should be noted. Firstly, even though our data cover the most important articles in the field of organisational culture, the database of recommended source website (Web of Science) by CiteSpace is not comprehensive and some important journals are excluded. SSCI collections in the Web of Science are from 2005; hence, the number of years of study for analysis is reduced. Secondly, the content of both citing and cited articles cannot be processed directly by CiteSpace; therefore, the details of important articles were analysed and interpreted manually, which is a time-consuming and relatively fallible procedure. Finally, information provided by both the Web of Science and CiteSpace is just a brief introduction to the publications, so we may lose some of the critical details in the full papers. Therefore, these three limitations are still problems to be solved in further studies.

\section{Acknowledgements Competing interests}

The authors declare that they have no financial or personal relationships that may have inappropriately influenced them in writing this article.

\section{Authors' contributions}

All authors contributed equally to the conceptualisation of the study. Y.C. wrote the article and was predominantly responsible for carrying out the data analysis. J.M. wrote the article and was predominantly responsible for carrying out result interpretation. Y.L. and J.M. finalised the article for submission.

\section{References}

Abramo, G., D'Angelo, C.A. \& Viel, F., 2011, 'The field-standardized average impact of national research systems compared to world average: The case of Italy', Scientometrics 88(88), 599-615. https://doi.org/10.1007/s11192-011-0406-x

Alavi, M. \& Leidner, D.E., 2006, 'An empirical examination of the influence of organizational culture on knowledge management practices', Journal of Management Information Systems 22(3), 191-224. https://doi.org/10.2753/ MIS0742-1222220307

Barney, J., 1991, 'Firm resources and sustained competitive advantage', Journal of Management 17, 99-120. https://doi.org/10.1177/014920639101700108

Barney, J.B., 1986, 'Organizational culture: Can it be a source of sustained competitive advantage?', Academy of Management Review 11(11), 656-665. https://doi.org/ $10.2307 / 258317$

Barney, J.B., 1995, 'Looking inside for competitive advantage', Academy of Management Executive 9(4), 49-61. https://doi.org/10.5465/AME.1995.9512 032192

Barney, J.B. \& Hansen, M.H., 1995, 'Trustworthiness as a source of competitive advantage: Barney, J.B. and Hanson, M. H. Strategic Management Journal 15 175-190 (winter 1995)', Long Range Planning 28(4), 127. https://doi.org/10.1016 /0024-6301(95)94297-C

Boyce, A.S., Nieminen, L.R.G., Gillespie, M.A., Ryan, A.M. \& Denison, D.R., 2015, 'Which comes first, organizational culture or performance? A longitudinal study of causal priority with automobile dealerships', Journal of Organizational Behavior 36(3), 339-359. https://doi.org/10.1002/job.1985

Büschgens, T., Bausch, A. \& Balkin, D.B., 2013, 'Organizational culture and innovation: A meta-analytic review', Journal of Product Innovation Management 30(4), 763-781. https://doi.org/10.1111/jpim.12021

Brettel, M., Chomik, C. \& Flatten, T.C., 2015, 'How organizational culture influences innovativeness, proactiveness, and risk-taking: Fostering entrepreneurial orientation in SMEs', Journal of Small Business Management 53(4), 868-885. https://doi.org/10.1111/jsbm.12108

Cameron, K.S. \& Quinn, R.E., 1998, Diagnosing and changing organizational culture: Based on the competing values framework, Addison-Wesley Press, New York.

Chatman, J.A., Caldwell, D.F., O'Reilly, C.A. \& Doerr, B., 2014, 'Parsing organizational culture: How the norm for adaptability influences the relationship between
culture consensus and financial performance in high-technology firms', Journal of culture consensus and financial performance
Organizational Behavior 35(6), 785-808(24).

Chen, C., 2006, 'CiteSpace II: Detecting and visualizing emerging trends and transient patterns in scientific literature', Journal of the Association for Information Science and Technology 57(3), 359-377. https://doi.org/10.1002/asi.20317

Chen, C., 2013, Mapping scientific frontiers, Springer, London.

Chen, D., Liu, Z., Luo, Z., Webber, M. \& Chen, J., 2016, 'Bibliometric and visualized analysis of emergy research', Ecological Engineering 90, 285-293. https://doi org/10.1016/j.ecoleng.2016.01.026

Deal, T.E. \& Kennedy, A., 1982, Corporate cultures: The rites and rituals of corporate life, Addison-Wesley Reading, Cambridge, MA.

Denison, D.R. \& Mishra, A.K., 1995, 'Toward a theory of organizational culture and effectiveness', Organization Science 6(2), 204-223. https://doi.org/10.1287/ orsc.6.2.204

Deshpandé, R., Farley, J.U. \& Webster Jr, F.E., 1993, 'Corporate culture, customer orientation, and innovativeness in Japanese firms: A quadrad analysis', The Journal of Marketing 57(1), 23-37. https://doi.org/10.2307/1252055

Diem, A. \& Wolter, S.C., 2013, 'The use of bibliometrics to measure research performance in education sciences', Research in Higher Education 54(1), 86-114. https://doi.org/10.1007/s11162-012-9264-5

Eddleston, K.A., Kellermanns, F.W. \& Floyd, S.W., 2013, 'Planning for growth: Life stage differences in family firms', Entrepreneurship Theory and Practice 37(5), $1177-$ 1202. https://doi.org/10.1111/etap.12002

Eddleston, K.A., Kellermanns, F.W. \& Sarathy, R., 2008, 'Resource configuration in family firms: Linking resources, strategic planning and technological opportunities to performance', Journal of Management Studies 45(1), 26-50.

Engelen, A., 2010, 'Entrepreneurial orientation as a function of national cultura variations in two countries', Journal of International Management 16(4), 354-368. https://doi.org/10.1016/j.intman.2010.09.006

Engelen, A., Flatten, T.C., Thalmann, J. \& Brettel, M., 2014, 'The effect of organizational culture on entrepreneurial orientation: A comparison between Germany and Thailand', Journal of Small Business Management 52(4), 732-752. https://doi. org/10.1111/jsbm.12052

Feng, F., Zhang, L., Du, Y. \& Wang, W., 2015, 'Visualization and quantitative study in bibliographic databases: A case in the field of university-industry cooperation', Journal of Informetrics 9(1), 118-134. https://doi.org/10.1016/j.joi.2014.11.009

Fey, C.F. \& Denison, D.R., 2003, 'Organizational culture and effectiveness: Can American theory be applied in Russia', Organization Science 14(6), 686-706. https://doi.org/10.1287/orsc.14.6.686.24868

Fornell, C. \& Larcker, D.F., 1981, 'Evaluating structural equation models with unobservable variables and measurement error', Journal of Marketing Research 18(1), 39-50. https://doi.org/10.2307/3151312

Gillespie, M.A., Denison, D.R., Haaland, S., Smerek, R. \& Neale, W.S., 2008, 'Linkin organizational culture and customer satisfaction: Results from two companies in different industries', European Journal of Work \& Organizational Psychology 17(1), 112-132. https://doi.org/10.1080/13594320701560820

Goll, I. \& Sanbharya, B., 1990, 'The effect of organizational culture and leadership on firm performance', Advances in Strategic Management 6, 183-200.

Gregory, B.T., Harris, S.G., Armenakis, A.A. \& Shook, C.L., 2009, 'Organizational culture and effectiveness: A study of values, attitudes, and organizational outcomes', Journal of Business Research 62(7), 673-679. https://doi.org/10.1016/j.jbusres. 2008.05.021

Harris, L.C. \& Ogbonna, E., 2007, 'The impact of cultural and political dynamics on web site design, development, and implementation', Personnel Review 36(6), 918938. https://doi.org/10.1108/00483480710822436

Hartnell, C.A., Ou, A.Y. \& Kinicki, A., 2011, 'Organizational culture and organizational effectiveness: A meta-analytic investigation of the competing values framework's theoretical suppositions', Journal of Applied Psychology 96(4), 677-694. https:// doi.org/10.1037/a0021987

Hatch, M.J., 1993, 'The dynamics of organizational culture', Academy of Management Review 18(4), 657-693.

He, H. \& Baruch, Y., 2009, 'Transforming organizational identity under institutional change', Journal of Organizational Change Management 22(6), 575-599. https:// doi.org/10.1108/09534810910997014

Hofstede, G., 1980, Culture's consequences: International differences in work-related values, Sage, Beverly Hills, CA.

Hofstede, G., 1998, 'Identifying organizational subcultures: An empirical approach', Journal of Management Studies 35(1), 1-12. https://doi.org/10.1111/14676486.00081

Hofstede, G. \& Geert, H., 1980, Culture's consequences: International differences in work-related values, Sage, Beverly Hills, CA. 
Hofstede, G., Neuijen, B., Ohayv, D.D. \& Sanders, G., 1990, 'Measuring organizational cultures: A qualitative and quantitative study across twenty cases', Administrative cultures: A qualitative and quantitative study across twenty cases', Admi
Science Quarterly 35(2), 286-316. https://doi.org/10.2307/2393392

Hofstede, G.H., 2001, Culture's consequences, second edition: Comparing values, behaviors, institutions and organizations across nations, vol. 41, pp. 924-931, Sage, Thousand Oaks, CA.

Hogan, S.J. \& Coote, L.V., 2013, 'Organizational culture, innovation, and performance: A test of Schein's model', Journal of Business Research 67(8), 1609-1621. https:// doi.org/10.1016/j.jbusres.2013.09.007

Homburg, C. \& Pflesser, C., 2000, 'A multiple-layer model of market-oriented organizational culture: Measurement issues and performance outcomes', Journal of Marketing Research 37(4), 449-462. https://doi.org/10.1509/jmkr.37.4.449.18786

Hong, T.M.B., Baruch, Y., Chau, V.S. \& He, H.W., 2016, 'Team learning: The missing construct from a cross-cultural examination of higher education', Asia Pacific Journal of Management 33(1), 29-51. https://doi.org/10.1007/s10490-015 9426-z

Huhtala, M., Kaptein, M. \& Feldt, T., 2015b, 'How perceived changes in the ethical culture of organizations influence the well-being of managers: A two-yea longitudinal study', European Journal of Work \& Organizational Psychology 25(3), 335-352. https://doi.org/10.1080/1359432X.2015.1068761

Huhtala, M., Tolvanen, A., Mauno, S. \& Feldt, T., 2015a, 'The associations between ethical organizational culture, burnout, and engagement: A multilevel study' Journal of Business and Psychology 30(2), 399-414. https://doi.org/10.1007/ Journal of Business

Kangas, M., Feldt, T., Huhtala, M. \& Rantanen, J., 2014, 'The corporate ethical virtues scale: Factorial invariance across organizational 'samples', Journal of Business Ethics 124(1), 161-171. https://doi.org/10.1007/s10551-013-1851-7

Kellermanns, F.W., Eddleston, K.A., Sarathy, R. \& Murphy, F., 2012, 'Innovativeness in family firms: A family influence perspective', Small Business Economics 38(1) 85-101. https://doi.org/10.1007/s11187-010-9268-5

Kessel, F.G.A.V., Oerlemans, L.A.G. \& Stroe-Biezen, S.A.M.V., 2014, 'No creative person is an island: Organisational culture, academic project-based creativity, and the mediating role of intraorganisational social ties', South African Journal of Economic \& Management Sciences 17(1), 46-69.

Kilmann, R.H., Saxton, M.J. \& Serpa, R., 1987, 'Gaining control of the corporate culture', Administrative Science Quarterly 32(3), 484. https://doi.org/10.2307/ 2392931

Kirca, A.H., Cavusgil, S.T. \& Hult, G.T.M., 2009, 'The effects of national culture on market orientation: Conceptual framework and research propositions' International Business Review 18(2) 111-118. https://doi.org/10.1016/j.ibusrev. 2009.02.003

Kokt, D. \& Merwe, C.A.V.D., 2011, 'Using the competing values framework (CVF) to investigate organisational culture in a major private security company', South African Journal of Economic \& Management Sciences 12(3), 343-352. https://do org/10.4102/sajems.v12i3.225

Kotrba, L.M., Gillespie, M.A., Schmidt, A.M., Smerek, R.E. \& Ritchie, S.A., 2012, ‘Do consistent corporate cultures have better business performance? Exploring the interaction effects', Human Relations 65(2), 241-262. https://doi.org/ 10.1177/0018726711426352

Lamsa, A., Kangas, M., Feldt, T. \& Huhtala, M., 2013, 'Ethical managers in ethica organisations? The leadership-culture connection among Finnish managers', Leadership \& Organization Developr
org/10.1108/01437731311326684

Lloyd C.H. \& Ogbonna, E., 2011, 'Motives for service sabotage: An empirical study of front-line workers', Service Industries Journal 32(13), 2027-2046.

Lorsch, J.W., 1985, Strategic Myopia: Culture as an invisible barrier to change, JosseyBass, San Francisco, CA.

Louis, M.R., 1980, 'Surprise and sense making: What newcomers experience in entering organizational settings', Administrative Science Quarterly 25, 226-251. https://doi.org/10.2307/2392453

Ma, F. \& Xi, M., 1992, 'Status and trends of bibliometric', Journal of Information Science 13(5), 7-17.

Mayr, P. \& Scharnhorst, A., 2014, 'Scientometrics and information retrieval: Weaklinks revitalized', Scientometrics 102(3), 2193-2199. https://doi.org/10.1007/ s11192-014-1484-3

Menguc, B. \& Auh, S., 2008a, 'The asymmetric moderating role of market orientation on the ambidexterity-firm performance relationship for prospectors and on the ambidexterity-firm performance relationship for prospectors and
defenders', Industrial Marketing Management 37(4), 455-470. https://doi. org/10.1016/j.indmarman.2007.05.002

Menguc, B. \& Auh, S., 2008b, 'Conflict, leadership, and market orientation', International Journal of Research in Marketing 25(25), 34-45. https://doi. org/10.1016/j.jiresmar.2007.08.001

Menguc, B. \& Auh, S., 2010, 'Development and return on execution of product innovation capabilities: The role of organizational structure', Industrial Marketing Management 39(5), 820-831. https://doi.org/10.1016/j.indmarman.2009.08.004
Menguc, B., Auh, S. \& Shih, E., 2007, 'Transformational leadership and market orientation: Implications for the implementation of competitive strategies and business unit performance', Journal of Business Research 60(4), 314-321. https:// doi.org/10.1016/j.jbusres.2006.12.008

Ogbonna, E. \& Harris, L.C., 2007, 'Developing internet operations and subcultural dynamics: An exploratory study', Journal of Organizational Change Management 20(3), 388-408. https://doi.org/10.1108/09534810710740209

Ogbonna, E. \& Harris, L.C., 2014, 'Organisational cultural perpetuation: A case study of an English premier league football club', British Journal of Management 25(4), 667-686. https://doi.org/10.1111/1467-8551.12037

O'Reilly, C.A., Caldwell, D.F., Chatman, J.A. \& Doerr, B., 2014, 'The promise and problems of organizational culture: CEO personality, culture, and firm performance', Group \& Organization Management 39(6), 595-625. https://doi. org $/ 10.1177 / 1059601114550713$

O’Reilly, C.A., Chatman, J. \& Caldwell, D.F., 1991, 'People and organizational culture: A profile comparison approach to assessing person-organization fit', Academy of Management Journal 34(3), 487-516. https://doi.org/10.2307/256404

Ouchi, W.G., 1981, Theory Z: How American business can meet the Japanese challenge, Addison-Wesley, Reading, MA

Pascale, R.T. \& Athos, A.G., 1982, The art of Japanese management, Allen Lane, London.

Peters, T.J. \& Waterman, H.R., 1984, In search of excellence: Lessons from America's best-run companies, Jr Warner Books, Waterman, IL.

Pettigrew, A., 1979, 'On studying organizational culture', Administrative Sciences Quarterly 24, 570-581. https://doi.org/10.2307/2392363

Podsakoff, P.M., Mackenzie, S.B., Lee, J.Y. \& Podsakoff, N.P., 2003, 'Common method biases in behavioral research: A critical review of the literature and recommended remedies', Journal of Applied Psychology 88(5), 879-903. https://doi. org/10.1037/0021-9010.88.5.879

Quinn, R.E. \& Spreitzer, G.M., 1991, 'The psychometrics of the competing values culture instrument and an analysis of the impact of organizational culture on quality of life', Research in Organizational Change and Development 5, 115-142.

Ravasi, D. \& Schultz, M., 2006, 'Responding to organizational identity threats: Exploring the role of organizational culture', Academy of Management Journal 49(49), 433-458. https://doi.org/10.5465/AMJ.2006.21794663

Slater, S.F., Hult, G.T.M. \& Olson, E.M., 2010, 'Factors influencing the relative importance of marketing strategy creativity and marketing strategy importance of marketing strategy creativity and marketing strategy implementation effectiveness', Industrial Marketing
559. https://doi.org/10.1016/j.indmarman.2008.03.007

Schein, E.H., 1985, Organizational culture and leadership, Josey-Bass, San Francisco, CA.

Schein, E.H., 1992, Organizational culture and leadership, Jossey-Bass, San Francisco, CA.

Schein, E.H., 2004, Organizational culture and leadership, 3rd edn., Jossey-Bass, San Francisco, CA.

Schneider, B., Brief, A.P. \& Guzzo, R.A., 1996, 'Creating a climate and culture for sustainable organizational change', Organizational Dynamics 24(4), 7-19. https:// doi.org/10.1016/S0090-2616(96)90010-8

Sheridan, J.E., 1992, 'Organizational culture and employee retention', Academy of Management Journal 35(5), 1036-1056. https://doi.org/10.2307/256539

Small, H., 2003, 'Paradigms, citations, and maps of science: A personal history', Journal of the Association for Information Science and Technology 54(5), 394-399. https://doi.org/10.1002/asi.10225

Strese, S., Adams, D.R., Flatten, T.C. \& Brettel, M., 2013, 'Corporate culture and absorptive capacity: The moderating role of national culture dimensions on innovation management', International Business Review 25(5), 1149-1168. https://doi.org/10.1016/j.ibusrev.2016.02.002

Strese, S., Meuer, M.W., Flatten, T.C. \& Brettel, M., 2015, ‘Organizational antecedents of cross-functional coopetition: The impact of leadership and organizational structure on cross-functional coopetition', Industrial Marketing Management 53, 42-55. https://doi.org/10.1016/j.indmarman.2015.11.006

Tellis, G.J., Prabhu, J.C. \& Chandy, R.K., 2013, 'Radical innovation across nations: The pre-eminence of corporate culture', Journal of Marketing a Quarterly Publication of the American Marketing Association 73(1), 3-23.

Tsui, A.S., Wang, H. \& Xin, K.R., 2006, 'Organizational culture in China: An analysis of culture dimensions and culture types', Management \& Organization Review 2(2), 345-376. https://doi.org/10.1111/j.1740-8784.2006.00050.x

Wan, G., Morgan, P.J. \& Barro, R.J., 2016, 'Economic growth and convergence, applied to China', China \& World Economy 24(5), 5-19. https://doi.org/10.1111/ cwe.12172

Weich, K.E., 1985, The significance of corporate culture, Sage, Beverly Hills, CA.

Zheng, W., Yang, B. \& Mclean, G.N., 2010, 'Linking organizational culture, structure, strategy, and organizational effectiveness: Mediating role of knowledge management', Journal of Business Research 63(7), 763-771. https://doi.org/ 10.1016/j.jbusres.2009.06.005 